\title{
Dose-response effects of equine chorionic gonadotrophin (eCG) and human chorionic gonadotrophin (hCG) on early embryonic development and viable pregnancy rate in rats
}

\author{
C. F. Tain, H. H. V. Goh* and S. C. Ng \\ Department of Obstetrics and Gynaecology, National University of Singapore, National \\ University Hospital, 5 Lower Kent Ridge Road, Singapore 119076
}

\begin{abstract}
The present study examined the dose-response effects of eCG treatment alone and in combination with various doses of hCG on early embryonic development in vivo and viable pregnancy rate in rats. Mated female Wistar rats were treated with eCG alone $(0,10,20$ or $40 \mathrm{iu})$, or with 20 iu eCG in combination with various doses of hCG (10, 20,40 or $80 \mathrm{iu}$ ) administered $48 \mathrm{~h}$ later. The animals were killed on days 2, 3, 4, 5 or 14 of pregnancy and the numbers of embryos and fetuses recovered were scored. All rats treated with 0 or 10 iu eCG were pregnant. The pregnancy rate was reduced from $62.5 \%$ on day 2 to $25 \%$ on day 14 and from $31 \%$ on day 2 to $10 \%$ on day 14 in the groups treated with 20 and 40 iu eCG, respectively. The
\end{abstract}

reduction in pregnancy rate induced by 20 iu eCG was negated by the increasing doses of hCG used. A $100 \%$ pregnancy rate was noted on days 2 and 3 in the groups treated with doses of hCG between 10 and 80 iu and from day 2 to day 4 in the groups treated with doses of hCG between 20 and 80 iu. However, a higher viable pregnancy rate was observed only in the group treated with $10 \mathrm{iu}$ hCG compared with the group treated with 20 iu eCG and 0 iu hCG. These results imply that hyperstimulation of rats with high doses of eCG compromises pregnancy rate and markedly reduces litter size and that the addition of hCG is required for complete ovulation, which results in higher embryo yield and a delay in early embryo demise.

\section{Introduction}

The low pregnancy rates in farm and laboratory animals, despite high oocyte yield after hyperstimulation with exogenous administration of eCG, could be the result of a high incidence of over-maturity (Moor et al., 1985) and chromosomal aberrations in oocytes (Hansmann et al., 1988; Badenas et al., 1989; Yun et al., 1989). It has also been suggested that the disrupted pattern of steroidogenesis after hyperstimulation might create an environment that is hostile to normal and sustained embryonic development, leading to failed pregnancy in immature rats (Miller and Armstrong, 1981). Therefore, it is possible that low pregnancy rates after hyperstimulation with gonadotrophins might be attributable to poor oocyte quality and a compromised microenvironment that is hostile to early embryonic development.

hCG is given routinely to induce ovulation, as a substitute for the LH surge; thus, poor pregnancy outcome could also be attributed to the dose of hCG used (Ertzeid and Storeng, 1992; Ertzeid et al., 1993). The aim of the present study was to examine the dose-response effects of eCG treatment alone and in combination with various doses of hCG on early embryonic development in vivo and on viable pregnancy rate using a rat model.

*Correspondence

Email: obggohhh@nus.edu.sg

\section{Materials and Methods}

\section{Animals}

Mature female Wistar rats (200-250 g body weight, aged 7-8 weeks) were housed in the Animal Holding Unit at a temperature of $28-30^{\circ} \mathrm{C}$ and kept under a $12 \mathrm{~h}$ light: $12 \mathrm{~h}$ dark photoperiod. The animals had free access to water and food chow (Glen Forrest Stockfeeders, Glen Forrest, WA). Fertile Wistar male rats were used for mating.

\section{Gonadotrophin administration}

A total of 706 mature female rats was injected i.p. with 0 , 10, 20 or 40 iu eCG (Sigma, St Louis, MO) in $0.5 \mathrm{ml}$ normal saline between $12: 00$ and $12: 30 \mathrm{~h}$ on the day of early dioestrus, followed by $0.5 \mathrm{ml}$ saline $48-52 \mathrm{~h}$ later. In some animals injected initially with 20 iu eCG, instead of the saline injection $48-52 \mathrm{~h}$ later, separate groups were administered with various doses of hCG $(10,20,40$ or $80 \mathrm{iu}$; Pregnyl; Oragon, Holland). Each female rat was caged with a fertile male overnight for mating (day 0 ). Successful mating was confirmed by the presence of spermatozoa in vaginal smears taken on the next day, which was designated as day 1 of pregnancy. Only rats that had mated successfully were included in the study.

\section{Embryo retrieval}

Groups of pregnant rats were killed (by excessive inhalation of carbon dioxide) between 09:30 and 10:00 h 
on days 2, 3, 4 or 5 of pregnancy. The oviducts and uterine horns were excised and flushed with T6 medium ( $\mathrm{Ng}, 1986)$ to retrieve embryos, which were examined and scored under a phase-contrast microscope. Embryos with regular blastomeres, intact zonae pellucidae and even granulation of the cytoplasm were classified as embryos with normal morphology, whereas embryos with irregular blastomeres, or those that were degenerating or fragmented were classified as embryos with abnormal morphology.

In other groups, pregnancy was allowed to progress up to day 14 , at which time the animals were killed (by excessive inhalation of carbon dioxide) to check the viability of the pregnancy. The total number and number of normal, abnormal and resorbed fetuses (a black spot with no visible fetus) were counted. Only the average total number and mean number of normal embryos and fetuses were used for the statistical analyses.

\section{Statistical analysis}

SPSS statistical software was used to analyse the experimental data. The mean total and average numbers of normal embryos and fetuses retrieved from the various treatment groups were analysed using Kruskal-Wallis or Mann-Whitney tests. The chi-squared test was used to analyse the pregnancy rates in different treatment groups. Differences were considered to be statistically significant when the $P$ value was $\leqslant 0.05$.

\section{Results}

\section{Pregnancy rates}

For the analyses, a positive pregnancy was defined as the presence of at least one embryo or fetus. In the control group and the group treated with 10 iu eCG, all rats $(100 \%)$ were pregnant on days 2-5 and day 14 of pregnancy (Fig. 1a). However, in the groups treated with 20 and 40 iu eCG, the pregnancy rate was compromised as early as day 2 and the pregnancy rates were $62.5 \%$ and $31 \%$, respectively. These rates were significantly reduced (chi-squared, $P<0.05$ ) as pregnancy progressed, and reached a minimum of $25 \%$ and $10 \%$ on day 14 in the groups treated with 20 and 40 iu eCG, respectively (Fig. 1a).

Various doses of hCG were administered to rats hyperstimulated with 20 iu eCG. The reduced pregnancy rates on days $2-4$ in the group treated with 20 iu eCG + 0 iu hCG were restored to $100 \%$ by doses of hCG between 20 and 80 iu (chi-squared, $P<0.05$; Fig. 1b). In the group treated with 10 iu hCG, the restoration of pregnancy rate to $100 \%$ was noted on days 2 and 3 (Fig. 1b). However, by day 14 , the pregnancy rates in all groups treated with hCG were not different from those in the group treated with 0 iu hCG.

\section{Number and quality of embryos}

The administration of 10 iu eCG significantly increased the average total number of embryos compared with that in the control group on days 2-5 of pregnancy, and the number of embryos with normal morphology on days 3-5 (Table 1). However, the increases in the number of embryos were not reflected in an increased number of viable fetuses on day 14 of pregnancy.

As with pregnancy rates, the average total number of embryos and number of embryos with normal morphology in the groups treated with 20 and 40 iu eCG were markedly reduced from day 2 to day 14, particularly in the group treated with 40 iu eCG (Table 1). Embryo demise occurred at an early stage, that is, by day 2 , in the group treated with 40 iu eCG (Table 1).

Significantly larger numbers of embryos with normal morphology were observed in the groups given doses of hCG between 10 and 80 iu (Table 2). The numbers of embryos in all groups treated with hCG were significantly larger than those in the group treated with 0 iu hCG. Increases in the total number of embryos and number of embryos with normal morphology in the groups treated with hCG ranged from two- to ninefold. However, by day 5 and day 14 , the total number and mean number of normal embryos and fetuses in the groups treated with hCG had decreased significantly and were not significantly different from the corresponding values in the group treated with $0 \mathrm{iu}$ hCG.

\section{Discussion}

The present study was undertaken to ascertain the effects of eCG administered to stimulate multiple folliculogenesis on early embryonic development and viable pregnancy rate in rats. The aims were: (i) to determine the dose-response effects of eCG on early embryonic development; (ii) to determine whether there is an optimal dose for oocyte quality and embryonic development; and (iii) to determine whether additional doses of hCG are required for the complete ovulation of the expanded cohort of preovulatory follicles and improvement in embryonic development and viability of pregnancy.

The largest number of embryos was retrieved from the group of rats treated with 10 iu eCG, which was about $56 \%$ higher than the number retrieved from the control group. Furthermore, increasing the dose of eCG to $\geqslant 20$ iu did not result in a higher pregnancy rate and yield of embryos and fetuses from day 2 to day 14 of pregnancy. A high degree of embryo loss was observed from day 2 to day 5 in the eCGtreated group: the percentage of embryos with normal morphology at day 2 that developed into viable fetuses was $77 \%$ and $23 \%$, respectively, in the groups treated with 10 and $20 \mathrm{iu}$ eCG. The reduction in the number of viable fetuses in the group treated with 10 iu eCG (mildly stimulated) implies that embryos with normal morphology did not necessarily have the potential to develop normally and lead to sustained pregnancy. Although many studies have shown that embryo loss is attributed to high oestrogen concentrations after hyperstimulation (Walton and Armstrong, 1981), measurement of oestrogen concentrations 

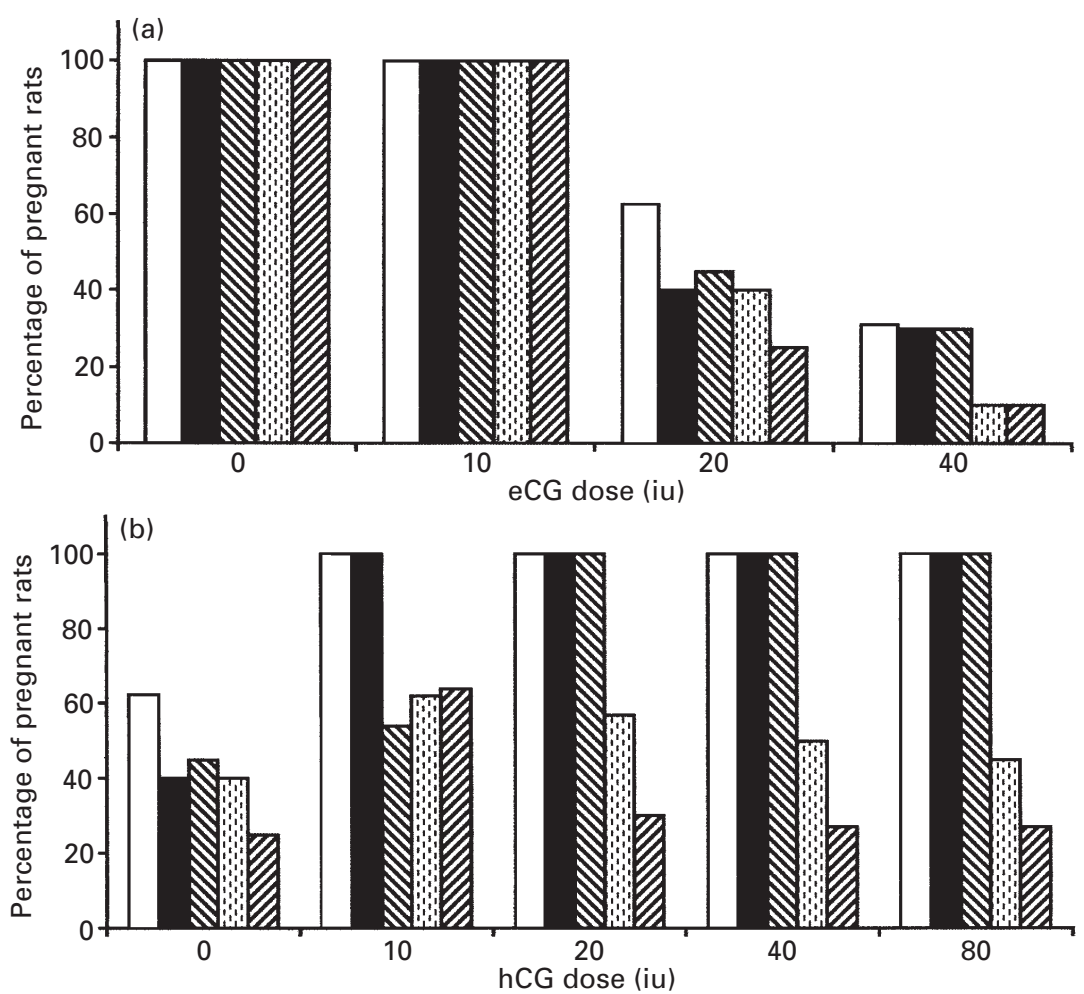

Fig. 1. Effects of (a) eCG alone ( $0-40 \mathrm{iu}$ ) and (b) $20 \mathrm{iu}$ eCG in combination with various doses of hCG $(0,10,20,40$ and $80 \mathrm{iu})$ on pregnancy rates in rats on days $2(\square), 3(\mathbf{\square})$, $4(\mathbf{N}), 5(\mathbf{W})$ and $14(\mathbb{Z})$ of pregnancy. Percentage of pregnant rats = number of pregnant rats/total number of rats in the treatment group. (a) Pregnancy rates in the groups treated with 20 and 40 iu eCG were significantly reduced from day 2 to day 14 of pregnancy $\left({ }^{*}\right.$ chi-squared, $P<0.05$ ). (b) Within groups treated with $0,10,20,40$ and 80 iu hCG, pregnancy rates were significantly reduced from day 2 to day 14 (chisquared, $P<0.05$ ). Among groups treated with doses of hCG between 0 and $80 \mathrm{iu}$, pregnancy rates were significantly different on days $2-5$ of pregnancy (chi-squared, $P$ $<0.05)$, but there were no differences on day 14 of pregnancy.

at day 1 showed that the concentrations in the group treated with 10 iu eCG $\left(101 \pm 6.6 \mathrm{pg} \mathrm{ml}^{-1}\right)$ were not different from those in the control group $\left(98 \pm 3.3 \mathrm{pg} \mathrm{ml}^{-1}\right)(\mathrm{C}$. F. Tain and H. H. V. Goh, unpublished), indicating that, in the present study, embryo loss may be due, at least in part, to compromised oocyte or embryo quality.

It is evident that the embryonic development was compromised in rats hyperstimulated with doses of eCG $\geqslant 20 \mathrm{iu}$. In the group treated with $40 \mathrm{iu}$ eCG, an average of only 1.5 embryos was retrieved on day 2 , which may be the result of ovulation failure, as administration of high doses of eCG suppresses endogenous LH secretion (Greenwald and Roy, 1994). However, other problems may be associated with the use of high doses of eCG. One possibility is that the long half-life and high LH-like activities of eCG may be detrimental to oocytes and early preimplantation embryos (Walton and Armstrong, 1981). The high LH-like activity of
eCG may cause over-maturation of the oocytes before they are ovulated. In other studies, embryo demise has been attributed to impaired oocyte quality (Moor et al., 1985), genetically abnormal oocytes (Hansmann et al., 1988; Badenas et al., 1989; Yun et al., 1989) and a hostile hormonal milieu in the reproductive tract induced by hyperstimulation (Miller and Armstrong, 1981).

The results from the present study indicate that the optimal dose for stimulating mature rats is about 10 iu eCG and that eCG doses of $\geqslant 20$ iu (given alone) impair early embryonic development, which eventually leads to low viable pregnancy rates. Furthermore, it was shown that embryo demise in hyperstimulated animals occurred early in pregnancy, that is, at the preimplantation stage. It is possible that embryo demise could be the result of a hostile environment created by the hyperstimulation (Walton et al., 1983) and this possibility is the subject of ongoing reaserch 
Table 1. Effects of administration of eCG on pregnancy outcome, the mean total number of embryos and the number of normal embryos or fetuses (mean \pm SEM) retrieved at days 2, 3, 4, 5 and 14 of pregnancy in rats

\begin{tabular}{|c|c|c|c|c|c|}
\hline \multirow{2}{*}{$\begin{array}{l}\text { Day of } \\
\text { pregnancy }\end{array}$} & & \multicolumn{4}{|c|}{ Dose of eCG (iu) } \\
\hline & & 0 & 10 & 20 & 40 \\
\hline \multirow[t]{3}{*}{2} & $n$ & $19 / 19$ & 10/10 & 10/16 & $4 / 13$ \\
\hline & Embryos* & $11.6 \pm 0.4^{\mathrm{a}}$ & $19.5 \pm 4.1$ & $14.4 \pm 3.9$ & $1.5 \pm 0.8^{\mathrm{b}}$ \\
\hline & Normal embryos ${ }^{\dagger}$ & $10.4 \pm 0.5$ & $15.1 \pm 3.4$ & $9.9 \pm 2.8$ & $0.7 \pm 0.3^{b}$ \\
\hline \multirow[t]{3}{*}{3} & $n$ & $18 / 18$ & 10/10 & $6 / 15$ & $3 / 10$ \\
\hline & Embryos & $11.3 \pm 0.5^{\mathrm{a}}$ & $16.4 \pm 2.1$ & $9.0 \pm 3.6$ & $6.6 \pm 3.8^{a}$ \\
\hline & Normal embryos & $9.7 \pm 0.5$ & $14.5 \pm 2.0^{\mathrm{c}}$ & $8.0 \pm 3.4$ & $5.4 \pm 3.6^{d}$ \\
\hline \multirow[t]{3}{*}{4} & $n$ & 18/18 & $10 / 10$ & $5 / 11$ & $3 / 10$ \\
\hline & Embryos & $11.2 \pm 1.1$ & $17.7 \pm 1.8^{\mathrm{c}}$ & $3.5 \pm 1.3^{d}$ & $2.9 \pm 2.0^{d}$ \\
\hline & Normal embryos & $10.1 \pm 1.0$ & $15.2 \pm 1.9^{c}$ & $2.8 \pm 1.1^{d}$ & $2.4 \pm 1.7^{d}$ \\
\hline \multirow[t]{3}{*}{5} & $n$ & $19 / 19$ & $11 / 11$ & $5 / 12$ & $1 / 10$ \\
\hline & Embryos & $10.3 \pm 2.3^{\mathrm{a}}$ & $15.5 \pm 1.7$ & $7.8 \pm 2.5$ & $0.9 \pm 0.9^{b}$ \\
\hline & Normal embryos & $9.7 \pm 0.6$ & $14.0 \pm 1.4^{\mathrm{c}}$ & $5.4 \pm 1.7$ & $0.7 \pm 0.7^{b}$ \\
\hline \multirow[t]{3}{*}{14} & $n$ & $20 / 20$ & $10 / 10$ & $3 / 12$ & $1 / 12$ \\
\hline & Embryos & $12.6 \pm 0.4$ & $14.6 \pm 1.8$ & $4.1 \pm 2.0^{d}$ & $1.0 \pm 1.0^{\mathrm{d}}$ \\
\hline & Normal embryos & $11.5 \pm 0.5$ & $11.6 \pm 1.3$ & $2.3 \pm 1.2^{\mathrm{de}}$ & $0.6 \pm 0.6^{b}$ \\
\hline
\end{tabular}

$n$ : number of pregnant rats/total number of rats.

*Embryos: mean total number of embryos; ${ }^{\dagger}$ normal embryos: mean number of embryos with normal morphology.

aSignificantly lower than corresponding values in the group treated with 10 iu eCG.

bSignificantly lower than corresponding values in all other groups.

cSignificantly higher than corresponding values in all other groups.

dSignificantly lower than corresponding values in the groups treated with 0 and 10 iu eCG.

eSignificantly lower than corresponding values on day 2 in the group treated with 20 iu eCG.

Values are statistically significant when $P \leqslant 0.05$.

Table 2. Effects of administration of 20 iu eCG and various doses of hCG on pregnancy outcome, the mean total number of embryos and the number of embryos with normal morphology (mean \pm SEM) retrieved at days 2, 3, 4, 5 and 14 of pregnancy in rats

\begin{tabular}{|c|c|c|c|c|c|c|}
\hline \multirow{2}{*}{\multicolumn{2}{|c|}{$\begin{array}{l}\text { Day of } \\
\text { pregnancy }\end{array}$}} & \multicolumn{5}{|c|}{ Dose of hCG (iu) } \\
\hline & & 0 & 10 & 20 & 40 & 80 \\
\hline \multirow[t]{3}{*}{2} & $n$ & $10 / 16$ & 10/10 & 10/10 & 10/10 & $10 / 10$ \\
\hline & Embryos* & $14.4 \pm 3.9^{\mathrm{e}}$ & $34.9 \pm 7.6^{a}$ & $28.8 \pm 3.8^{b}$ & $34.2 \pm 6.3^{b}$ & $35.6 \pm 7.6^{b}$ \\
\hline & Normal embryos ${ }^{\dagger}$ & $9.9 \pm 2.8^{\mathrm{e}}$ & $27.3 \pm 4.9^{a}$ & $26.2 \pm 3.4^{b}$ & $29.2 \pm 4.6^{b}$ & $26.6 \pm 6.6^{b}$ \\
\hline \multirow[t]{3}{*}{3} & $n$ & $6 / 15$ & 10/10 & $10 / 10$ & $11 / 11$ & 10/10 \\
\hline & Embryos & $9.0 \pm 3.6^{c}$ & $28.6 \pm 5.0^{\mathrm{a}}$ & $22.9 \pm 4.1^{b}$ & $36.5 \pm 6.8^{b}$ & $42.1 \pm 6.6^{b}$ \\
\hline & Normal embryos & $8.0 \pm 3.4^{\mathrm{e}}$ & $26.6 \pm 4.7^{a}$ & $20.2 \pm 3.9^{b}$ & $28.2 \pm 5.0^{b}$ & $33.9 \pm 5.7^{b}$ \\
\hline \multirow[t]{3}{*}{4} & $n$ & $5 / 11$ & $8 / 14$ & $11 / 11$ & $10 / 10$ & $11 / 11$ \\
\hline & Embryos & $3.5 \pm 1.3^{f}$ & $10.9 \pm 3.6^{d}$ & $18.4 \pm 3.7^{b}$ & $30.1 \pm 4.4^{b}$ & $31.7 \pm 3.2^{b}$ \\
\hline & Normal embryos & $2.8 \pm 1.1^{f}$ & $9.0 \pm 3.1^{f}$ & $17.4 \pm 3.6^{b}$ & $25.2 \pm 4.5^{b}$ & $25.0 \pm 4.1^{b}$ \\
\hline \multirow[t]{3}{*}{5} & $n$ & $5 / 12$ & 9/14 & $8 / 14$ & $6 / 12$ & $5 / 11$ \\
\hline & Embryos & $7.8 \pm 2.5$ & $6.2 \pm 2.0$ & $4.8 \pm 1.5$ & $6.3 \pm 2.3$ & $3.9 \pm 1.6$ \\
\hline & Normal embryos & $5.4 \pm 1.7$ & $5.5 \pm 1.7$ & $4.6 \pm 1.4$ & $6.1 \pm 2.2$ & $3.9 \pm 1.6$ \\
\hline \multirow[t]{3}{*}{14} & $n$ & $3 / 12$ & $7 / 11$ & $3 / 10$ & $3 / 11$ & $3 / 11$ \\
\hline & Embryos & $4.1 \pm 2.0$ & $10.8 \pm 2.8$ & $7.1 \pm 3.4$ & $8.7 \pm 3.4$ & $6.1 \pm 3.2$ \\
\hline & Normal embryos & $2.3 \pm 1.2$ & $7.9 \pm 2.0$ & $3.7 \pm 2.5$ & $3.5 \pm 2.2$ & $3.2 \pm 2.1$ \\
\hline
\end{tabular}

$n$ : number of pregnant rats/total number of rats.

*Embryos: mean total number of embryos; ${ }^{\dagger}$ normal embryos: mean number of embryos with normal morphology.

aSignificantly higher than the value at days 4, 5 and 14 within the same hCG group.

bSignificantly higher than the value at days 5 and 14 within the same hCG group.

cSignificantly lower than corresponding values in the groups treated with 10, 40 and 80 iu hCG.

dSignificantly lower than corresponding values in the groups treated with 40 and 80 iu hCG.

eSignificantly lower than corresponding values in all other groups.

fSignificantly lower than corresponding values in the groups treated with 20, 40 and 80 iu hCG.

Values are statistically significant when $P \leqslant 0.05$. 
in our centre, which includes transferring two-cell embryos from hyperstimulated rats into non-stimulated pseudopregnant rats.

This is the first study to show that administration of hCG (10-80 iu) to rats hyperstimulated with eCG can increase embryo yield and improve pregnancy rates, which is in contrast to the studies by Ertzeid and Storeng (1992) and Ertzeid et al. (1993). The various doses of hCG administered after injection of 20 iu eCG induced between two and five times more embryos on days 2 and 3 than the corresponding values in the group treated with 20 iu eCG alone. This finding implies that, in the rats treated with 20 iu eCG alone, the endogenous LH surge was probably inadequate to induce ovulation. Therefore, the administration of exogenous hCG can trigger the maturation and ovulation of the expanded cohort of follicles. However, there were no doserelated increases in the number of embryos retrieved with increasing doses of hCG.

These findings imply that additional hCG not only resulted in more complete ovulation of the expanded cohort of preovulatory follicles, but that the hCG resulted in an increase in the quality of the oocytes and subsequent embryos such that more rats were able to sustain pregnancy beyond the implantation stage. However, the positive effect of administration of 10 iu hCG was not enhanced when the dose was increased. This finding implies that the addition of hCG was unable to reverse the embryo demise caused by high doses of eCG administered earlier, even though the cohort of early embryos was much larger.

The results of the present study indicate that rats hyperstimulated with a high dose of eCG have compromised pregnancy rates and markedly reduced litter sizes. Furthermore, in hyperstimulated cases, the addition of high doses of hCG might be required for complete ovulation as well as for improving the maturation of the expanded cohort of preovulatory follicles. There also appears to be a critical threshold value for the additional hCG used in rats.

The financial support from the National University of Singapore is gratefully acknowledged. The authors would also like to thank the staff from the Animal Holding Unit for taking care of the experimental animals and the staff from the Obstetrics and Gynaecology Research Laboratory who helped in one way or another.

\section{References}

Badenas J, Santalo J, Calafell JM, Estop AM and Egozcue J (1989) Effects of the degree of maturation of mouse oocytes at fertilization: a source of chromosome imbalance Gamete Research 24 205-218

Ertzeid G and Storeng R (1992) Adverse effects of gonadotrophin treatment on pre- and post-implantation development in mice Journal of Reproduction and Fertility 96 649-655

Ertzeid G, Storeng R and Lyberg T (1993) Treatment with gonadotrophins impaired implantation and fetal development in mice Journal of Assisted Reproduction and Genetics $10286-291$

Greenwald GS and Roy SK (1994) Follicular development and its control. In The Physiology of Reproduction Vol. 1 pp 629-724 Eds E Knobil and JD Neill. Raven Press, New York

Hansmann I, Boer Pde and Speed RM (1988) Aneuploidy-related delay of meiotic development in the mouse and the djungarian hamster. In The Cytogenetics of Mammalian Autosomal Rearrangements pp 295-314 Ed. A Daniel. Alan R Liss, Inc, New York

Miller BG and Armstrong DT (1981) Effects of a superovulatory dose of pregnant mare serum gonadotrophin on ovarian function, serum estradiol, and progesterone levels and early embryo development in immature rats Biology of Reproduction 25 261-271

Moor RM, Osborn JC and Crosby IM (1985) Gonadotrophin-induced abnormalities in sheep oocytes after superovulation Journal of Reproduction and Fertility 74 167-172

Ng SC (1986) Laboratory Manual for IVF. Department of Obstetrics and Gynaecology, National University of Singapore

Walton EA and Armstrong DT (1981) Ovarian function and early embryo development in immature rats given a superovulatory dose of PMSG, later neutralised by antiserum Biology of Reproduction 25 272-280

Walton EA, Evans G and Armstrong DT (1983) Ovulation response and fertilisation failure in immature rats induced to superovulate Journal of Reproduction and Fertility 67 91-96

Yun YW, Yu FH, Yuen BH and Moon YS (1989) Effects of a superovulatory dose of pregnant mare serum gonadotrophin on follicular steroid contents and oocyte maturation in rats Gamete Research 23 289-298

Received 15 January 2001.

First decision 19 February 2001.

Accepted 26 April 2001. 